\title{
Editorial
}

\section{Drug withdrawal a common feature attributed to patient safety}

\author{
Sunil Chaudhry ${ }^{1, *}$ \\ ${ }^{1}$ Honorary Médical Director, Bioclinitech Technologies Pvt Ltd, Mumbai, India \& GPATtutor.com
}

\section{A R T I C L E I N F O}

Article history:

Received 20-10-2021

Accepted 27-10-2021

Available online 19-11-2021
This is an Open Access (OA) journal, and articles are distributed under the terms of the Creative Commons Attribution-NonCommercial-ShareAlike 4.0 License, which allows others to remix, tweak, and build upon the work non-commercially, as long as appropriate credit is given and the new creations are licensed under the identical terms.

For reprints contact: reprint@ipinnovative.com
At the end of the day, the goals are simple, safety and security

\section{Need For Withdrawing Drug From The Market}

Unexpected adverse effects, or SUSARs (untoward and unintended response to a study drug, which is not listed is the applicable product information) harmful interactions, continued irrational use and not adequate risk management plan for the marketed product. ${ }^{1}$ The adverse effects are detected though a process of regular monitoring after the drug is released called pharmacovigilance, which is now dominant process in country regulated through Pharmacovigilance Programme in India, which is steered by Central Drugs Standard Control Organization, New Delhi. Fixed dose combinations are nearly 4 times more in India, than the developed countries, the basic reason for their introduction into market was better drug compliance, rather taking the two drugs separately. In the domestic market, FDCs (Fixed drug combinations) were contributing to $>50$ $\%$ sales in the market. The rationality of FDC is not known much to clinicians. The Drugs Technical Advisory Board recommended that "there is no therapeutic justification" for the ingredients contained in the 344 FDC drugs and that these medicines "may involve risk to human beings". ${ }^{2}$ and thus these were removed from Indian market in March $15^{\text {th }}$ $2016 .^{3}$

\footnotetext{
* Corresponding author.

E-mail address: sunil.r.chaudhry@gmail.com (S. Chaudhry).
}

\subsection{Spectrum of withdrawal}

The drugs withdrawn globally in the past decade were nonsteroidal antiinflammatory drugs $(28 \%)$, antidiabetics (14.28\%), antiobesity (14.28\%), antihistamines (14.28\%), prokinetic drugs $(7.14 \%)$, breast cancer and infertility drugs (7.14\%), irritable bowel syndrome and constipation drugs (7.14\%) and antibiotics (7.14\%). ${ }^{4}$ The widely used antiobesity drugs fenfluramine and dexfenfluramine have been recalled in the various countries in the wake of continuing reports that their use is contributing to heart-valve defects. Most of the drugs that affect monoamine neurotransmitters licensed for the treatment of obesity over the past 65 years have been withdrawn because of adverse reactions.

Drugs may be withdrawn even after they are available in the market for a decade or longer. Examples of such drugs include are Rosiglitazone, Rofecoxib, Gatifloxacin, and Rimonabent formulations used in the market over a decade.

It has been shown that the higher the fluoroquinolone dose ( Sparfloxacin, Grepafloxacin , Moxifloxacin) and serum AUCs, the higher the QT prolongation risk. Moxifloxacin is used to evaluate the drugs which can cause relative QTc prolongation.

There is a paradox, there are certain drugs not available in US and EU but are still marketed in India such as Analgin , Droperidol, Furazolidone, Nitrofurazone, Oxyphenbutazone, Nimesulide and Piperazine. However, the Union Ministry of Health and Family Welfare finally 
Table 1: Chronology of drug withdrawal of some vital molecules

\begin{tabular}{lcc}
\hline Drug & Therapeutic Class & $\begin{array}{c}\text { Year Withdrawn } \\
\text { from Market }\end{array}$ \\
Prenylamine & Angina & 1988 \\
Terodiline & Urinary & 1991 \\
Sparfloxacin & Incontinence & \\
Terafenadine & Antibiotic & 1996 \\
Sertindole & Antispsychotic & 1998 \\
Astemizole & Antihitamine & 1998 \\
Grepafloxacin & Antibiotic & 1999 \\
Cisapride & Prokinetic & 1999 \\
Droperidol & Antipsychotic & 2000 \\
Levomethadyl & Opiate Dependence & 2001 \\
Propoxyphene & Analgesic & 2003 \\
\hline
\end{tabular}

had decided to suspend the pediatric use of the Nimesulide suspension from 10 March 2011 Nimesulide formulations are not indicated for use in children below 12 years of age. The drug was banned in 2000 in various countries like Switzerland, Spain, and United states. ${ }^{5}$

In 2011, Pioglitazone was withdrawn from the French market owing to a potential risk of bladder cancer. U.S. Food and Drug Administration (FDA) is informing the public that use of the diabetes medication Actos (pioglitazone) for more than one year may be associated with an increased risk of bladder cancer. ${ }^{6}$ Information about this risk will be added to the Warnings and Precautions section of the label for pioglitazone-containing medicines. In India drug was withdrawn from Indian market but was reintroduced in Indian market as safety concern was only in animal studies and there were cost constraints

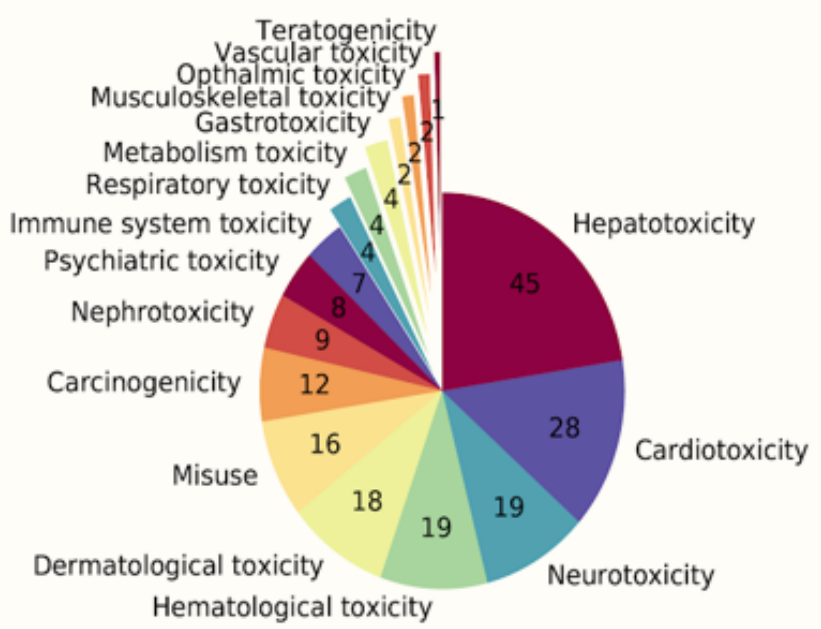

Fig. 1: Depending on toxicity on various organs, the drug withdrawal is categorised

As evident from pie, most of drugs have been withdrawn due to Hepatoxicity, Cardiotoxicity, Neurotoxicity and the abnormal Haematological profile.
Recently, FDA has found N-nitrosodimethylamine (NDMA) levels in some ranitidine products increase with time and temperature posing a risk to consumers, and therefore the agency has requested the withdrawal of all ranitidine products from the U.S. market. In September 2019, Ranatidine was withdrawn by many generic companies in India and then it was reintroduced. Sartans such as Candesartan and Olmesartan also have such impurities.

Cerivastatin was approved in 1997 in US. Low doses were effective $(0.2 \mathrm{mg}, 0.3 \mathrm{mg}$ and $0,4 \mathrm{mg})$ It is indicated as an adjunct to diet to reduce elevated Total-C, LDL$\mathrm{C}$, apo $\mathrm{B}$, and $\mathrm{TG}$ and to increase HDL-C levels in patients with primary hypercholesterolemia and mixed dyslipidemia High dose cerivastatin $\{0.8 \mathrm{mg}$ ) along with Gemfibrozil 600mg caused Rhabdomyolysis in patients. This drug-drug interaction was implicated fatalities in the United States and Spain Cerivastatin was withdrawn on $9^{\text {th }}$ August 2001. ${ }^{7}$ Cerivastatin was withdrawn from the market because of 52 deaths attributed to drug-related rhabdomyolysis that lead to kidney failure. FDA restricted Rosiglitazone use in February 2010 after studies linked the drug to increased risk of heart attacks. Rosiglitazone was also withdrawn from the New Zealand market in April 2011.

\subsection{Financial Implications of drug withdrawal}

Monetary loss to marketing company which runs in million of dollars, which comes as process of recall from market and litigations from users and finally the image of corporate needs to be maintained

\section{Source of funding}

None.

\section{Conflict of Interest}

None.

\section{References}

1. Ahmad A, Patel I, Sanyal S, Balkrishnan R, Mohanta GP. A Study on Drug Safety Monitoring Program in India. Indian J Pharm Sci. 2014;76(5):379-86.

2. List of drugs prohibited as per CDSCO site, 26 A of 1940. Available from: https://cdsco.gov.in/opencms/resources/UploadCDSCOWeb/ 2018/UploadConsumer/banneddrugs.pdf.

3. Pariente A, Mansiaux Y, Jarné A, Salvo F, Pageot C, Bezin J. Impact of pioglitazone regulatory withdrawal on antidiabetic drug use and health in diabetic patients. Eur J Clin Pharmacol. 2017;73(12):1655-63. doi: $102007 / \mathrm{s} 00228-017-2326-7$.

4. Begam RF, kumar YR, Velmurugan R. Awareness about FDA announcement on voluntary recall of ranitidine among physicians and pharmacists in and around Chennai, India: a cross-sectional study. Future J Pharm Sci. 2021;7:112.

5. Furberg CD, Pitt B. Withdrawal of cerivastatin from the world market. Curr Control Trials Cardiovasc Med . 2001;2(5):205-7. doi-10. $186 / \mathrm{cvm}-2-5-205$ 
6. Complete list of 344 drugs banned by the Ministry of Health Family welfare I National Health Portal Of India; 2016. Available from: https://www.nhp.gov.in/Complete-list-of-344-drugs-banned-bythe-Ministry-of-Health-Family-welfare.

7. Fiona M. Drug Safety Data Curation and Modeling in ChEMBL: Boxed Warnings and Withdrawn Drugs. Chem Res Toxicol. 2018;34(2):385-

95. 10101021/acs.chemrestox 0c00296

\section{Author biography}

Sunil Chaudhry, Honarary Medical Director, Bioclinitech Technologies Pvt Ltd Mumbai India

Cite this article: Chaudhry S. Drug withdrawal a common feature attributed to patient safety. J Pharm Biol Sci 2021;9(2):70-72. 